\title{
Human antibody-mediated T-cell suppression for kidney transplantation
}

Suppression of acute cellular alloimmunity, without eliciting adverse reactions, is vital to the overall outcome of kidney transplantation. New results from a phase II clinical trial represent an important step towards achievement of this key objective.

A wide range of immunosuppressive agents are able to prevent T-cell mediated acute rejection, but adverse events and graft rejection are an ongoing concern, especially in highly sensitized patients. Using the novel IgM antibody TOL101 to suppress cellular rejection, Stuart Flechner and collaborators observed rapid and robust T-cell modulation, lower rates of acute rejection and fewer adverse events in kidney transplant recipients $(n=36)$ than those typically observed with currently used T-cell strategies.

TOL101 is a mouse-derived antibody that targets the $\alpha \beta$ subunits of the human T-cell receptor. The study showed that TOL101 modulates T-cells without mitogenicity, or the acute cytokine release syndrome that is typically associated with biological therapies. "The half-life of IgM antibodies is much shorter than IgG antibodies," explains Flechner, which might account for the less-severe adverse event profile. A subset of patients $(n=4)$ developed urticarial rash in response to the highest tested doses of TOL101 (42 mg). However, a doseescalation strategy (beginning at $14 \mathrm{mg}$ or $21 \mathrm{mg}$ and increasing to $42 \mathrm{mg}$ ) prevented this adverse reaction.

"TOL101 has been approved by the FDA for phase III study. We are developing a protocol and are in the process of securing funding," concludes Flechner.

\section{Peter Sidaway}

Original article Flechner, S. M. et al. First in human study of the safety and efficacy of TOL101 induction to prevent kidney transplant rejection. Am. J. Transplant. doi:10.1111/ ajt. 12698 